\title{
Study on mechanical characteristics of deep engineering rock materials
}

\author{
Taoli Xiao ${ }^{1,2, a^{*}}$, Ming Ai ${ }^{2, b}$, Fei Teng ${ }^{2, c}$ and Zhonglin Wang ${ }^{2, d}$ \\ ${ }^{1}$ School of Urban Construction Yangtze University, Jingzhou, Hubei 434023, China \\ ${ }^{2}$ Rock and Soil Mechanics Engineering Research Center, Yangtze University, Jingzhou, Hubei \\ 434023, China \\ axt19720209@163.com, bai19900323@163.com, ‘911670049@qq.com, d504612798@qq.com
}

\begin{abstract}
Keywords: Rock mechanics, Construction material, Marble, Strength parameters, Mechanical characteristics.

Abstract: According to the characteristics of deep diversion tunnel of Jinping II Hydropower Station located in the high field stress condition, for its surrounding rock, i.e. marble, the conventional triaxial test and pre-peak unloading test are carried out. Then study on its mechanical characteristics through the comparative analysis. The results show that: The peak strength increases according to the initial confining pressure increases, and even if the stress path and initial confining pressure is different, but as long as the real-time confining pressure, the peak strength is equal. Further, the change rule of mechanics parameters is the same under different stress paths. These conclusions have revealed the difference of mechanical properties of marble under loading and unloading conditions and provided reliable theoretical reference for the numerical simulation about excavation, designing and stability analysis of deep diversion tunnel in West China.
\end{abstract}

\section{Introduction}

Jinping Ilhydropower station is located in Jinping Mountain area surrounded by the bend of Yalong river, Liangshan prefecture, Sichuan. The hydropower station uses the $310 \mathrm{~m}$ natural drop of Jinping bend in Yalong River to generate electricity by cutting off the river channel and Excavating the tunnel. The length of the headrace tunnel is $16-19 \mathrm{~km}$, the excavation radius is $11 \mathrm{~m}$, the common depth is $1500-2000 \mathrm{~m}$, and the biggest one is $2525 \mathrm{~m}$. The lithology of the tunnel surrounding rock is complex, mainly in marble, sandstone, and maximum stress along the tunnel line is up to 54MPa. For studying the stability of deep surrounding rock during excavation, the conventional tri-axis test was carried out under different confining pressures, to research the unique mechanical characteristics of Jinping marble under high stress, supporting a theory reference of excavation, supporting design and stability analysis in deep underground engineering.

\section{Test program}

\section{Test conditions}

The test was carried out on the MTS815.03 Electro-hydraulic Servocontrolled Rock Mechanics Testing Machine. The whole process was controlled by the microcomputer, and the confining pressure was controlled by the stress, the axial load was controlled by the displacement. Samples taken from Jinping II hydropower station diversion tunnel, the depth is about $2100 \mathrm{~m}$, the rocks are thick-bedded marble of Baishan group $\left(\mathrm{T}_{2 \mathrm{~b}}\right)$. They are intact and no obvious structural planes or corrosion cracks. Sample size is $\phi 50 \mathrm{~mm} \times 100 \mathrm{~mm}$. The sample drying density is $2.70 \mathrm{~g} / \mathrm{cm}^{3}$, the elastic modulus is $24.13 \mathrm{GPa}$, Poisson's ratio is 0.282 , and the uniaxial compressive strength is $199.20 \mathrm{MPa}$.

\section{Test program}

Three groups of typical test scheme is designed, to study the deformation and failure characteristics of marble under unloading path, and then run the contrastive analysis with the characteristics of unloading stress path and conventional triaxral compression path. Make the following definitions: $\sigma_{0}$ represents for the initial confining pressure value designed for the unloading confining pressure test, $\sigma_{3}$ is expressed as the measured confining pressure in the 
experimental procedure, peak strength is the maximum value of the principal stress difference $\left(\sigma_{1}-\sigma_{3}\right)$ in the stress-strain curve, strength ratio is the percentage of peak strength between the unloading confining pressure test and triaxral compression test, and confining pressure ratio is the percentage of measured confining pressure and the initial confining pressure in the unloading confining pressure test.

Programme I (triaxial compression test)

In order to design the unloading point and the stress level of subsequent unloading test program, and its deformation, and make the comparative analysis with the results of deformation and intensity, at first, the entire process of triaxial compression test under constant confining pressure is carried out with the confining pressure design values of 10, 20, 30, 40, 60, 70, 50MPa. Conduct the test procedure according to the rules mentioned above.

Programme II (Unloading confining pressure test with constant axial pressure before the peak)

The test is divided into the following 4 stages: (1)Apply a certain pre loading to make the sample between the upper and lower heads fully fixed, and then manually apply the confining pressure to a predetermined initial confining pressure values of $20,40,60 \mathrm{MPa}$ by the rating of $0.1 \mathrm{MPa} / \mathrm{s}$; (2) Keep $\sigma_{0}$ steady, and gradually increase $\sigma_{1}$ to a stress state until the specimen is destroyed (that is, the critical unloading point), which is based on the results of the program I, according to $75 \%$ of the peak intensity; (3)To keep the constant of $\sigma_{1}$, but also gradually decrease $\sigma_{3}$ to the destruction of the sample at the rate of $0.05 \mathrm{MPa} / \mathrm{s}$; (4)Continue to apply the stress until the stress difference $\left(\sigma_{1}-\sigma_{3}\right)$ does not decrease with the increase of the axial strain and the end of the test.

Programme III (Unloading confining pressure test with constant axial pressure after the peak)

This test program consists three phases: (1)This stage is same with the stage one of the programme II; (2) Keep $\sigma_{0}$ steady, and gradually increase $\sigma_{1}$ to yield limit, which is based on the results of the program I and the real-time test curve shape; Stop applying $\sigma_{1}$, once the real-time curve is close to the peak intensity of programme I and appears the softening trend; key of the stage is whether it can effectively determine unloading point, which to make the curve smooth over peak into the softening stage; (3)To keep the constant of $\sigma_{1}$, but also gradually decrease $\sigma_{3}$ to the destruction of the sample.

\section{Mechanical characteristics analysis}

\section{Analysis of peak intensity}

After making the statistics of the relationships between peak strength and confining pressure of different stress paths in the test, the results are shown in Fig.1, 2 and Table 1.

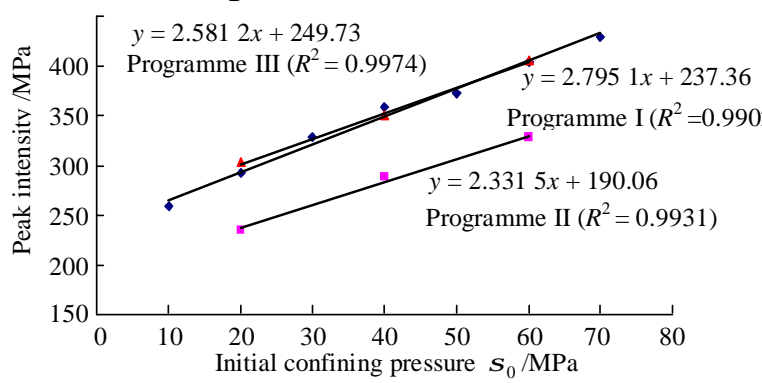

Fig.1 Relationship between peak strength and initial confining pressure of marble under different stress paths

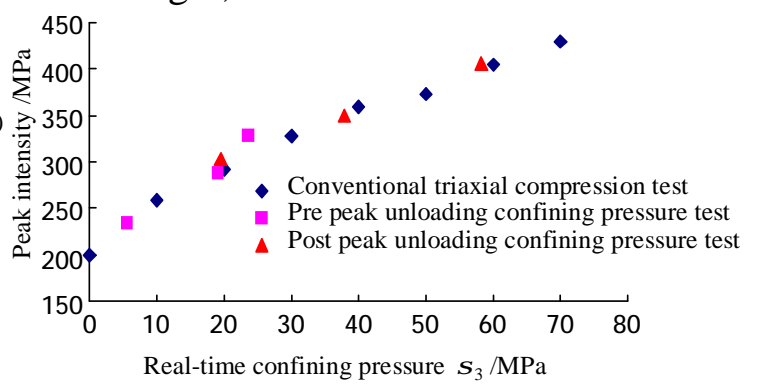

Fig.2 Relationship between peak strength and confining pressure of marble 
Fig. 1 shows that the peak intensity of the sample is sensitive for the confining pressure, and three kinds of test programs data is linear fitting; the linear correlation coefficients of three kinds of programs are above 0.99; no matter is the conventional triaxial compression test, or before or after peak unloading confining pressure tests, with the increase of initial confining pressure, the peak strength of the samples show a good linear increase.

Table 1 Relationship between peak strength and confining pressure of marble

\begin{tabular}{cccccc}
\hline $\begin{array}{c}\text { Initial confining } \\
\text { pressure } \\
\sigma_{0}[\mathrm{MPa}]\end{array}$ & $\begin{array}{c}\text { Test program } \\
\text { number }\end{array}$ & $\begin{array}{c}\text { Peak } \\
\text { intensity[MPa] }\end{array}$ & $\begin{array}{c}\text { Strength ratio } \\
{[\%]}\end{array}$ & $\begin{array}{c}\text { Real-time } \\
\text { confining } \\
\text { pressure[MPa] }\end{array}$ & $\begin{array}{c}\text { Ratio of real-time } \\
\text { confining pressure and } \\
\text { initial confining } \\
\text { pressure [\%] }\end{array}$ \\
\hline \multirow{2}{*}{20} & I & 292.04 & & 20.00 & \\
& II & 234.46 & 80.3 & 5.61 & 28.1 \\
40 & III & 302.88 & 103.7 & 19.46 & 97.3 \\
& I & 358.49 & & 40.00 & 47.7 \\
& II & 287.81 & 80.3 & 19.07 & 97.2 \\
& III & 359.93 & $100.4 \%$ & 38.86 & 39.6 \\
& I & 404.96 & & 60.00 & 97.1 \\
\hline
\end{tabular}

After making a statistical analysis of the peak strength of specimen under different stress paths and the corresponding confining pressure, Fig. 2 shows that even if the stress path is different and the initial confining pressure is different, the peak strength of the specimen also shows approximately equal trend, once the confining pressure is similar.

Fig. 1 and table 1 show that compared with the conventional triaxial compression test, the pre peak unloading confining pressure test makes the peak intensity decreased by about $19.5 \%$, and the post peak unloading confining pressure test has little effect on the peak strength; the confining pressure corresponding to the peak intensity show a large randomness in the pre peak unloading confining pressure test, and the confining pressure corresponding to the peak intensity of the post peak unloading confining pressure test is about $97.2 \%$ of the initial confining pressure.

For further analysis of the effects of the per peak unloading confining pressure test and post peak unloading confining pressure test on the sample strength, here introduce the concepts of unloading point and unloading ratio. The unloading point is expressed as the ratio between the deviator stress strength at the beginning of unloading confining pressure in the unloading confining pressure test and the deviator stress peak strength in the conventional triaxial compression test. The unloading ratio indicates that the ratio between the deviator stress strength at the beginning of unloading confining pressure and the deviator stress peak strength in the unloading confining pressure test. Figure 3 shows the relationship between the unloading point and unloading ratio in the unloading confining pressure test. The following conclusions can be obtained by curves in Figure 3: the pre peak unloading point is about 0.75 and the unloading ratio is about 0.92 ; the post peak unloading point and the unloading ratio all are around 1.00; the curve of the pre peak unloading confining pressure is steeper than the curve of the post peak unloading confining pressure, which is represented that the energy absorbed by the pre peak unloading confining pressure is more than that of the post peak unloading confining pressure test. The reasons of this phenomenon are the following: there are cracks in the specimens at the stress state of the unloading point; because the crack damage is small, and the plastic deformation is little in the pre peak unloading confining pressure test, the destruction of the specimen must absorb enough energy and is sharp; before the post peak unloading confining pressure, the rock has experienced the yield deformation stage and has a large plastic deformation, and the micro cracks tend to run through, and the specimen also has absorbed a certain elastic deformation, so the specimen can achieve complete destruction by absorbing less energy when continue to unload confining pressure, and the specimen damage is relatively flat. 


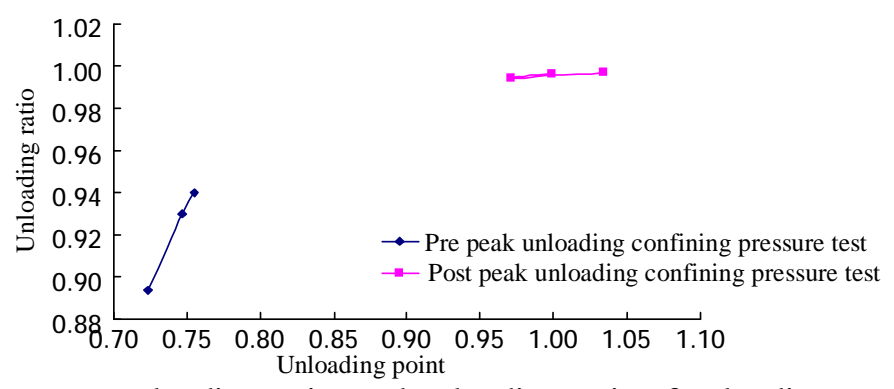

Fig.3 Relationship between unloading point and unloading ratio of unloading confining pressure tests

\section{Analysis of strength parameters}

Research shows that, the rock strength is not only related to its occurrence of geological environment $^{[1]}$, but also the loading and unloading rate ${ }^{[2,4]}$; Mohr $\sim$ Coulomb strength criterion is one of the most widely used in geotechnical engineering, and it is also widely used in the analysis by Wang Bin et $a^{[5,6]}$. The expression of $\mathrm{M} \sim \mathrm{C}$ strength criterion ${ }^{[7]}$ is the following formula:

$$
\tau=c+\sigma \tan \varphi
$$

(1)

In the formula, $\tau, \sigma$ are respectively expressed as shear stress and normal stress in shear failure plane, $c, \varphi$ are respectively represented as cohesion and internal friction angle of the sample. For the tri-axis test, $\sigma, \tau$ can be expressed as the following formulas:

$$
\left.\begin{array}{l}
\sigma=\frac{1}{2}\left(\sigma_{1}+\sigma_{3}\right)+\frac{1}{2}\left(\sigma_{1}-\sigma_{3}\right) \cos (2 \varphi) \\
\tau=\frac{1}{2}\left(\sigma_{1}-\sigma_{3}\right) \sin 2 \varphi
\end{array}\right\}
$$

(2)

In addition, for reducing the influence of the factors, and by using the results of the tri-axis test, the best straight line intercepted on the $\sigma_{1}: \sigma_{3}$ curve can be fitted to the following linear relationship:

$$
\sigma_{1}=m \sigma_{3}+b
$$

In the formula, $\tau, \sigma$ are respectively expressed as the slope and intercept of the linear fitting. The internal friction angle and cohesion of rock can be determined by these parameters as the following formulas:

$$
\varphi=\sin ^{-1}[(m-1) /(m+1)]
$$

$$
c=\frac{b}{2 \sqrt{m}}
$$

\begin{tabular}{|c|c|c|c|c|c|c|}
\hline \multirow{2}{*}{$\begin{array}{c}\text { Test program } \\
\text { number }\end{array}$} & \multicolumn{2}{|c|}{$m \sim c$ envelope method } & \multicolumn{2}{|c|}{$\sigma_{1} \sim \sigma_{3}$ curve method } & \multicolumn{2}{|c|}{ Average method } \\
\hline & $\mathrm{c}[\mathrm{MPa}]$ & $\varphi\left[{ }^{\circ}\right]$ & $\mathrm{c}[\mathrm{MPa}]$ & $\varphi\left[{ }^{\circ}\right]$ & $\mathrm{c}[\mathrm{MPa}]$ & $\varphi\left[{ }^{\circ}\right]$ \\
\hline I & 54.25 & 38.6 & 61.13 & 35.8 & 57.69 & 37.2 \\
\hline II & 41.46 & 46.1 & 42.16 & 45.2 & 41.81 & 45.6 \\
\hline III & 65.60 & 34.8 & 65.44 & 34.8 & 65.52 & 34.8 \\
\hline
\end{tabular}

Based on the test data in table 1 for reference, the shear strength parameters calculated by the formula (3) (5) under different stress paths are shown in table 2.

Table 2 Parameters of shear strength about marble under different stress paths

Analysing the shear strength parameters calculated by two different methods and listed in table 2 , the results show that the calculation results of the 2 methods in the programme I are quite 
different, and the results in the programme II are basically consistent, and the results in the programme III are very close. Thus, the unloading confining pressure test choose the $\mathrm{M} \sim \mathrm{C}$ envelope method or $\sigma_{1} \sim \sigma_{3}$ curve method to calculate the rock, while the conventional triaxial compression test, the average of the 2 methods is suggested for the calculations of $c, \varphi$.

Obviously, calculated by the $\mathrm{M} \sim \mathrm{C}$ envelope method, or the curve method, the strength parameters of the sample under the unloading path or loading path are different .Compared to the conventional triaxial compression test, in the pre peak unloading confining pressure test, the cohesion is reduced by about $27.5 \%$, and the friction angle is increased about $22.6 \%$; but in the post peak unloading confining pressure test, the cohesion is increased by about13.7\%, and the friction angle is reduced about $6.5 \%$; the pre peak unloading confining pressure test and the post peak unloading confining pressure test show the opposite effect on the strength parameters of marble. The reasons can be understood as: while the pre peak unloading confining pressure, the marble is in the primary stage of yield deformation, and its plastic deformation is small, and the rock begins to crack, and the fracture surface is controlled by the cohesive and the friction of rock; when the confining pressure is reduced, with the rock fracture and the plastic deformation increasing rapidly, the crack expands rapidly along the crack initiation angle; at this time, the main controlling factor of rock fracture resistance is the size of the friction.

Relatively speaking, while the post peak unloading confining pressure, the rock has experienced the stage of yield deformation, with a certain plastic deformation; the micro cracks tend to run through, and the micro fracture surfaces form basically. Because of the role of cohesion, the rock does not crack completely. The main controlling factor of rock fracture resistance is the cohesive, so when the influence of the cohesion increases, the friction reduces.

\section{Conclusions}

1. The confining pressure effect of the marble is obvious, and the peak strength is increaseed linearly with the confining pressure; its peak intensity is closely related to the real-time confining pressure; even if the stress path is different and the initial confining pressure is different, the peak strength of the specimen also shows approximately equal trend, once the confining pressure is similar. Compared with the conventional triaxial compression test, the pre peak unloading confining pressure test makes the peak intensity decreased by about $19.5 \%$, but the rule of the post peak unloading confining pressure test is not obvious; the confining pressure corresponding to the peak intensity of the post peak unloading confining pressure test is about $97.2 \%$ of the initial confining pressure, but the result of the pre peak unloading confining pressure test show a large randomness.

2. The relation between the unloading point and the unloading ratio is shown as follows: the curve of the pre peak unloading confining pressure is steeper than the curve of the post peak unloading confining pressure, which is represented that the energy absorbed by the pre peak unloading confining pressure is more than that of the post peak unloading confining pressure test.

3. Compared to the conventional triaxial compression test, in the pre peak unloading confining pressure test, the cohesion is reduced by about $27.5 \%$, and the friction angle is increased by $22.6 \%$; but in the post peak unloading confining pressure test, the cohesion is increased by about $13.7 \%$, and the friction angle is reduced by $6.5 \%$. In conclusion, in the pre peak unloading confining pressure test, the main controlling factor of rock fracture resistance is the size of the friction, but in the post peak unloading confining pressure test, the main controlling factor of rock fracture resistance is the cohesive.

\section{Acknowledgments}

This study was supported by Natural Science Fund of Hubei Province ( 2015CFB667 ) ; Science and Technology Research Projects of Hubei Province (Q20141307). 


\section{References}

[1] ZHOU Hongwei, XIE HePing, ZUO Jianping, et al: Experimental study of the effect of depth on mechanical parameters of rock. Chinese Science Bulletin, 2010, 55(34): 3276-3284.

[2] OLSSON W A: The compressive strength of tuff as a function of strain rate from $10^{-6}$ to 103/sec. In. J. Rock Mech. and Min. Sci., 1991, 28 (1): 115-118.

[3] JU Qinghai, WU Mianba: Experimental studies of dynamic characteristic of rocks under triaxial compression. Chinese Jounal of Geotechnical Engineering, 1993, 15(3): 73-80.

[4] ZHAO Y H, ZHAO J: Compressive strength of rock material at different strain rate. In: Yu M H ed. Proceedings of the International Symposium on Strength Theories' Applications and Developments. Xi'an, China: [s. n.], 1998, 75-429.

[5] WANG Bin, ZHU Jiebing, WU Aiqing, et al: Experimental study of mechanical properties of Jinping marble under loading and unloading stress paths. Chinese Journal of Rock Mechanics and Engineering, 2008, 27(10): 2138-2145.

[6] LU Yinghui, LIU Quansheng, HU Yunhua: Damage deformation characteristics and tits strength criterion base on unloading experiments of granites. Chinese Journal of Rock Mechanics and Engineering, 2009, 28(10): 2096-2102.

[7] CAI Meifeng, HE Manchao, LIU Dongyan: Rock Mechanics and Engineering. Beijing: Science Press, 2002. 